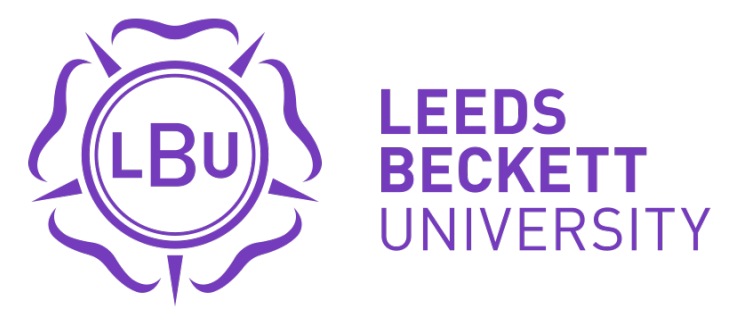

Citation:

Capio, CM and Poolton, JM and Eguia, KF and Choi, CS and Masters, RS (2017) Movement pattern components and mastery of an object control skill with error-reduced learning. Developmental Neurorehabilitation, 20 (3). 1 - 5. ISSN 1751-8423 DOI: https://doi.org/10.3109/17518423.2016.1140844

Link to Leeds Beckett Repository record:

https://eprints.leedsbeckett.ac.uk/id/eprint/2442/

Document Version:

Article (Accepted Version)

The aim of the Leeds Beckett Repository is to provide open access to our research, as required by funder policies and permitted by publishers and copyright law.

The Leeds Beckett repository holds a wide range of publications, each of which has been checked for copyright and the relevant embargo period has been applied by the Research Services team.

We operate on a standard take-down policy. If you are the author or publisher of an output and you would like it removed from the repository, please contact us and we will investigate on a case-by-case basis.

Each thesis in the repository has been cleared where necessary by the author for third party copyright. If you would like a thesis to be removed from the repository or believe there is an issue with copyright, please contact us on openaccess@leedsbeckett.ac.uk and we will investigate on a case-by-case basis. 


\section{Movement pattern components and mastery of an object control skill with error-reduced}

learning: Brief report

\section{Objectives}

This paper reports the effects of error-reduced learning on movement components and mastery of overhand throwing in children with and without intellectual disability.

\section{Methods}

Secondary data analysis was performed on two samples of children (typically developing, TD; intellectual disability, ID) who practiced overhand throwing in either an error-reduced (ER) or errorstrewn (ES) condition. Movement pattern components were assessed using a sub-skill of Test of Gross Motor Development-2.

\section{Results}

In TD participants, ER learners displayed improved follow-through while ES learners did not. Among children with ID, ER learners displayed greater improvements of hip/shoulder rotation and followthrough, than ES learners. Discriminant function analysis confirmed that changes in these components differentiated learning groups. Greater percentage of ER, compared to ES, participants progressed to mastery.

\section{Conclusions}

With suppressed errors, the follow-through component of overhand throwing is likely to emerge, particularly in children with inferior abilities, and working memory limitations. Error-reduced learning facilitates mastery.

Keywords: Object control, overhand throwing, error-reduced learning, intellectual disability 


\section{Introduction}

Proficiency in object control skills is an important aspect of child development as these skills are critical in physical activities of moderate to vigorous intensity, such as sports and games [1]. Object control skills impact health such that proficiency predicts cardiorespiratory fitness in adolescence among typically developing children [2]. Likewise, for children with intellectual disability, object control skills proficiency predicts sports participation [3] and habitual physical activity [4].

Object control skills, however, are particularly difficult to improve [5]. Children with and without disability tend to display lower mastery of object control compared to locomotor skills $[3,6]$. For the most part, this is due to the physical complexity of object control skills (e.g. transitional coordination, dexterity) [6]. Moreover, these skills are generally practiced in physical activity environments that require continual adaptation to changing circumstances (e.g. competitive games) [7]. Because heightened skill complexity raises the cognitive demands of object control tasks [8], movement training interventions are likely to be more effective when such factors are taken into account.

Suppression of errors during motor skills training is believed to reduce the cognitive demands placed on the learner and has been shown to be beneficial for children, probably because it accommodates the developing cognitive resources of children [9]. Referred to as errorless learning in the motor control literature, this approach constrains the learning environment to suppress the likelihood of practice errors and, thus, the need for the learner to actively seek solutions for successful motor task performance [10]. Operationally termed as error-reduced learning, this approach was shown to promote better overhand throw movement patterns and increased target accuracy among typically developing children, compared to a training intervention that allowed errors to occur freely [11]. Furthermore, children involved in error-reduced learning displayed throwing accuracy that was unaffected by the imposition of a cognitively demanding secondary task, suggesting that performance of the overhand throw was less dependent on cognitive resources. When replicated in children with intellectual disability, similar benefits were found [12]. These two studies provide evidence that suppression of errors in the early stages of learning an object control skill promotes movement patterns and target accuracy that do not appear to be dependent on cognitive resources. However, neither study 
reported the impact of error-reduced learning on the distinct movement components of the overhand throwing action. In examining the development of overhand throwing, Ulrich [13] identified performance criteria pertaining to movements of the arm, trunk, hip and feet, which represent components of a mature movement pattern. By evaluating these movement components, skill levels may be quantified [6], and impairments in performance can be more readily detected [13]. This facilitates the design of effective targeted intervention programs.

This paper reports a secondary analysis of data collected by Capio and colleagues $[12,13]$, which specifically examines changes in the components of the overhand throw movement pattern during error-reduced and error-strewn learning. The analysis identifies trends in the emergence of movement pattern components among typically developing children and those with intellectual disability. Examination of changes in overhand throwing movement pattern components is important for identifying mechanisms that underlie the benefits of error-reduced learning, and will provide a basis for interventions to help children with developmental impairment.

This analysis also quantified overhand throwing mastery as a potentially meaningful indicator of training effects. Mastery in the context of FMS, such as overhand throwing, has been quantified based on the consistent demonstration of all the components of the movement pattern [6]. Mastery is likely to be a meaningful outcome measure of a motor skill training program for clinicians because it indicates that a child has gained the ability for consistent skill performance.

\section{Method}

All procedures were reviewed and approved by the university institutional ethics review board, and had been reported in detail in two previously published papers [11,12].

Participants

The data analysed in this paper were from a sample of typically developing (TD) children $(n=108 ; 51$ females, 57 males) aged $9.10 \pm 1.12$ years old; and a sample of children categorized by their school to be with mild intellectual disability (ID) with nonverbal IQ ranging from 50 to 70, ( $\mathrm{n}=36$; 9 females, 27 males), and aged 7.22 \pm 2.07 years old. The TD sample was divided into a high-ability ( $\mathrm{n}=54)$ or a lowability group $(\mathrm{n}=53)$ based on pretest movement pattern scores. 


\section{Procedures}

For the TD sample, training consisted of three weekly sessions, with two bouts of 20 throws. The training for the ID sample consisted of two bouts of 15 throws over four weekly sessions (total for each sample: 120 throws). In the ER training condition, participants practiced throwing initially at a large square target, suppressing the occurrence of outcome errors in the early stage of learning. TD participants practiced throwing from a $5 \mathrm{~m}$ distance, at targets that were incrementally decreased in size per session: $2.4 \times 2.4 \mathrm{~m}, 1.1 \times 1.1 \mathrm{~m}$, and $0.45 \times 0.45 \mathrm{~m}$. The ID group practice throwing from a $2.5 \mathrm{~m}$ distance, at targets of incrementally decreasing sizes: $1.25 \times 1.25 \mathrm{~m}, 1.0 \times 1.0 \mathrm{~m}, 0.75 \times 0.75 \mathrm{~m}$, and 0.5 x $0.5 \mathrm{~m}$. In contrast, the ES training groups practiced with targets in reverse sequence, starting with the smallest target, allowing errors to occur. Performance (i.e. number of successful hits on the target) was monitored during practice, and compared between training conditions to verify the manipulation.

Proficiency was tested in two trials using the overhand throwing sub-skill, of the object control component of the Test of Gross Motor Development-2 (TGMD-2) [14]. TGMD-2 examines overhand throwing movement patterns in terms of four components: (1) hand/arm windup, (2) hip/shoulder rotation, (3) weight-shifting, and (4) follow-through. By observation, each component was determined to be either present $($ score $=1)$ or absent $($ score $=0)$ in each of the trials. The maximum possible score was eight across the two trials, representing mastery of the overhand throwing pattern [6]. The proportion of participants who displayed mastery was calculated and reported in percentages. Testing procedures were performed before (pretest) and after (posttest) training sessions.

Independent samples t-test was used to compare performance of ER and ES training groups during the practice sessions. Changes from pretest to posttest were calculated in each of the four movement pattern components, and were examined by multivariate analysis of variance (MANOVA). For the TD sample, factors were learning condition (ER, ES), ability (high, low) and sex (female, male). For the ID sample, the only factor was learning condition. Sex was not used as a factor due to the small number of females in the sample. Significant main effects were followed up by univariate ANOVA and discriminant function analysis. Significant interactions were followed up by independent samples ttests. To analyse mastery, the percentage of participants who displayed mastery was calculated 
separately for each of the learning conditions and compared using chi-square tests at pre-test and at post-test. Alpha was 0.05 for all tests.

\section{Results}

Performance scores (i.e. successful hits on the target) during the practice sessions was significantly higher in the ER than in the ES condition, for both the TD $(\mathrm{t}(100)=2.207, \mathrm{p}=0.03)$ and the ID $(\mathrm{t}(37)=2.17, \mathrm{p}=0.035)$ samples (see Table 1 for descriptive information on scores).

In the TD sample, MANOVA results showed significant main effects of learning condition $\left(\mathrm{F}(4,97)=2.55, p=0.044, \mathrm{\eta}^{2}=0.10\right)$, ability $\left(\mathrm{F}(4,97)=2.86, p=0.028, \mathrm{\eta}^{2}=0.11\right)$, and $\operatorname{sex}(\mathrm{F}(4,97)=4.33$, $p=0.003, \mathrm{\eta}^{2}=0.15$ ). A significant interaction between learning condition and sex was also found $\left(\mathrm{F}(4,97)=4.45, p=0.002, \eta^{2}=0.16\right)$. There was no significant interaction between learning condition and ability $\left(\mathrm{F}(4,97)=0.745, p=0.56, \eta^{2}=0.03\right)$; neither between ability and $\operatorname{sex}(\mathrm{F}(4,97)=1.67, p=0.16$, $\left.\eta^{2}=0.07\right)$.

Follow-up univariate ANOVAs showed that learning condition had a significant main effect only for the follow-through component $\left(\mathrm{F}(1,100)=4.48, p=0.037, \mathrm{\eta}^{2}=0.04\right)$, in which the ER group displayed improvements in follow-through while the ES group did not. Ability had a significant main effect only for the hip/shoulder rotation component $\left(\mathrm{F}(1,100)=5.08, p=0.026, \eta^{2}=0.05\right)$, in which improvement was greater for the low ability than the high ability group. Sex had significant main effects for the hand/arm windup $\left(\mathrm{F}(1,100)=5.56, p=0.02, \mathrm{\eta}^{2}=0.05\right)$ and weight-shifting $(\mathrm{F}(1,100)=4.88$, $\left.p=0.03, \eta^{2}=0.06\right)$ components.

Discriminant function analysis showed that changes in the movement pattern components accounted only for $8.89 \%$ of between group (ER, ES) variability, but the model was not statistically significant (Wilks' $\lambda=0.91, \chi^{2}=8.79, p=0.067$ ). Discriminant function coefficients showed a significant mean difference only in the follow-through component $(\mathrm{F}(1,106)=4.93, p=0.029)$, which was also the highest discriminant function coefficient $(0.83)$. Nevertheless, two other components were found with discriminant function coefficients >0.30: weight-shifting (0.59) and hand/arm wind-up (0.40).

To follow up the significant interaction between learning condition and sex, post-hoc analysis using independent samples t-tests showed that only females in the ER condition improved in the first 
three components: hand/arm windup $(\mathrm{t}(44)=2.24, p=0.03)$, hip/shoulder rotation $(\mathrm{t}(44)=2.83, p=0.007)$, and weight-shifting $(\mathrm{t}(44)=2.42, p=0.02)$. For the follow-through component, both males and females improved, hence no difference was evident $(\mathrm{t}(44)=-.08, p=0.939)$. In the ES condition, no significant differences were found between females and males in hand/arm windup $(\mathrm{t}(60)=1.41, p=0.17)$, hip/shoulder rotation $(\mathrm{t}(60)=-0.83, p=0.41)$, and weight-shifting $(\mathrm{t}(60)=1.08, p=0.28)$. A significant difference was found in follow-through $(\mathrm{t}(60)=2.19, p=0.03)$ because males appeared to become worse, whereas females improved (see Figure 1).

In the ID sample, MANOVA revealed a significant main effect of learning condition $\left(\mathrm{F}(4,34)=4.08, p=0.008, \eta^{2}=0.33\right)$. Follow-up univariate ANOVAs revealed significant main effects of learning condition for hip/shoulder rotation $\left(\mathrm{F}(1,37)=6.81, p=0.013, \mathrm{\eta}^{2}=0.16\right)$ and follow-through $\left(\mathrm{F}(1,37)=8.00, p=0.008, \eta^{2}=0.18\right)$. The main effect of learning condition was not significant for hand/arm windup $\left(\mathrm{F}(1,37)=0.91, p=0.35, \eta^{2}=0.024\right)$ and weight-shifting $(\mathrm{F}(1,37)=0.40, p=0.53$, $\eta^{2}=0.011$ ). As shown in Figure 1, the ER group displayed greater improvements in these two components than the ES group.

Discriminant functions showed that changes in the movement pattern components accounted for $33.99 \%$ of between group (ER, ES) variability (Wilks' $\lambda=0.66, \chi^{2}=14.52, p=0.006$ ). However, analysis of the discriminant function coefficients showed that only the changes in hip/shoulder rotation (0.655) and follow-through (0.731) differentiated the ER and ES learning conditions. The two other components had coefficients below 0.30 .

At pre-test, the percentage of TD participants who displayed mastery of overhand throwing movement pattern was comparable between the ER (47.8\%) and ES (46.8\%) groups $\left(\chi^{2}=0.012, p=0.91\right)$. At post-test, mastery had increased, but to a greater extent in the ER (87.0\%) than in the ES $(66.1 \%)$ group $\left(\chi^{2}=6.109, p=0.013\right)$. Among the ID participants, none of the ER group (0\%) and only one participant in the ES group (4.8\%) displayed movement pattern mastery at pre-test $\left(\chi^{2}=0.88, p=0.348\right)$. At post-test, more ER (62.5\%) than ES (37.5\%) participants displayed mastery, but probably due to the small sample size this difference was not statistically significant $\left(\chi^{2}=1.082, p=0.298\right)$. 


\section{Discussion}

Suppression of errors during the early stages of practice appears to benefit object control skills of children. Focusing on overhand throwing, error-reduced learning has been shown to develop skills that are less dependent on cognitive resources $[11,12]$. The current findings deepen our understanding by providing insight into possible mechanisms that facilitate learning of movement pattern components, and development of skill mastery.

In TD children, error-reduced learning promoted emergence of the follow-through component of the overhand throw better than error-strewn learning. Improved hand/arm wind-up and weightshifting could possibly characterize error-reduced learners as well, but the discriminant function analysis in this study appear to be of insufficient power. Therefore, we focus on the follow-through component, which is said to represent the rapid deceleration of the throwing arm following object release, which occurs with associated trunk and lower extremity motion to aid dissipation of energy [14]. Kinematic studies have shown that this distal component is directly associated with the force released by the thrower [15] and higher ball velocity [16]. One limitation of this study is that force or velocity was not measured, and future research may aim to measure kinematic variables to verify the current findings.

In other research, it has been suggested that learners may be encouraged to throw harder when no specific instructions regarding how to carry out the movement are given, or when focus of attention is directed externally (i.e. "increase ball velocity") [17]. External focus of attention may enable the body to self-organize without being constrained by conscious control, thus generating better outcomes [18]. Reduction of practice errors may similarly allow children to perform the object control skill without conscious movement monitoring.

Learners are likely to engage their cognitive resources to monitor and control movement in response to performance errors [10]. Suppression of errors may therefore progress learners to mastery by utilizing more implicit systems. It is likely that error-reduced learners displayed a more automatic movement pattern, releasing the object with greater force and displaying follow-through. In contrast, error-strewn learners may have exerted conscious control over their throwing movements, restricting 
force during object release. A recent study showed that learners with greater propensity for conscious monitoring and control of movement tended to be more attuned to errors during practice [19].

Because error-reduced learning tends to be less dependent on cognitive resources, it is potentially useful for children with lower working memory resources, such as the case of children with ID. The approach not only promoted emergence of the follow-through component of the overhand throw among children with ID, but also facilitated hip/shoulder rotation, which is a preparatory action by which the thrower gains momentum prior to object release contributing to velocity [15]. This component requires a well-coordinated contraction of hip and core musculature, which may be impaired in children with developmental disabilities due to deficits in integrating sensory feedback as a consequence of working memory limitations. Children with ID learnt to produce coordinated movement components, suggesting that the error-reduced approach may be particularly useful for those with working memory deficits. Nevertheless, it should be noted that the sample of children with ID in this study were younger than the TD sample, and had a greater range of scores to gain to reach maturity (see Table 1). Future studies should examine the critical age range, during which error-reduced object control skills training would be optimal for children with ID.

Developmental studies have shown that girls perform worse than boys in throwing parameters (e.g. patterns, forces) [20], likely due to biological (i.e. body size) or ecological (i.e. available opportunities) factors [21]. Our findings show that suppression of errors allowed girls to improve in all movement pattern components, thereby catching up to the boys who displayed movement patterns that were nearer mastery at pretest. If it were purely due to availability of practice, the girls in the errorstrewn learning condition should have been able to catch up with the boys as well. We therefore propose that for children with less developed object control skills (i.e. girls, children with ID), errorreduced practice would help them progress to mastery. We acknowledge that errors are relevant sources of information when learning [22], but our findings suggest that clinicians should consider promoting successful experiences, at least during the early stages of practice.

While overhand throwing movement pattern and accuracy had been shown to have statistically significant improvements based on our current findings, and those from previous studies $[11,12]$, this 
may not be synonymous with a clinically important change [23]. Moreover, statistical differences were not shown to have particularly large effect sizes. On the other hand, changes in mastery levels may be a relevant outcome measure of skill learning, as is apparent in epidemiological research that had described populations' motor skills proficiency in terms of mastery (e.g. preschoolers [6], children who are obese [24]). Practice, whether in ER or ES conditions, increased the number of children demonstrating mastery of overhand throwing; however, error-reduced learning led to a greater proportion of children reaching mastery following practice. Both samples completed a total of 120 practice throws over three to four weeks. For clinicians, this implies that overhand throwing mastery may be facilitated within a relatively short training period, and that suppression of errors may take more children towards mastery regardless of their cognitive abilities. As we recognize the importance of proficient object control skills in the development of children, these findings may be useful considerations for clinicians who design and implement training programs for children.

\section{Acknowledgments}

This study was supported in part by the Seed Funding Program for Basic Research of the University of Hong Kong, grant number 201405159002.

\section{Declaration of interest}

The authors report no declarations of interest.

\section{References}

[1] Raudsepp L, Pall P. The relationship between fundamental motor skills and outside-school physical activity of elementary school children. Pediatric Exercise Science 2006;18(4):426-435.

[2] Barnett LM, Van Beurden E, Morgan PJ, Brooks LO, Beard JR. Does Childhood Motor Skill Proficiency Predict Adolescent Fitness? Medicine and Science in Sports and Exercise 2008;40(12):2137-2144.

[3] Westendorp M, Houwen S, Hartman E, Visscher C. Are gross motor skills and sports participation related in children with intellectual disabilities? Research in Developmental Disabilities 2011;32(3):1147-1153. 
[4] Eguia KF, Capio CM, Simons J. Object control skills influence the physical activity of children with intellectual disability in a developing country: Philippines. Journal of Intellectual and Developmental Disability 2015;40(3): 265-274.

[5] Morgan PJ, Barnett LM, Cliff DP, Okely AD, Scott HA, Cohen KE, Lubans DR. Fundamental movement skill interventions in youth: a systematic review and meta-analysis. Pediatrics 2013;132(5):e1361-83.

[6] Hardy LL, King L, Farrell L, Macniven R, Howlett S. Fundamental movement skills among Australian preschool children. Journal of Science and Medicine in Sport 2010;13(5):503-508.

[7] Houwen S, Visscher C, Hartman E, Lemmink KAPM. Gross motor skills and sports participation of children with visual impairments. Research Quarterly for Exercise and Sport 2007;78(2):16-23.

[8] Latash M, Turvey M. Dexterity and its development. Mahwah, NJ: Lawrence Erlbaum Associates Inc.; 1996.

[9] Capio CM, Sit CH, Abernethy B, Masters RSW. The possible benefits of reduced errors in the motor skills acquisition of children. Sports Medicine Arthroscopy Rehabilitation Therapy \& Technology 2012;4:1.

[10] Maxwell JP, Masters RSW, Kerr E, Weedon E. The implicit benefit of learning without errors. Quarterly Journal of Experimental Psychology A 2001;54(4):1049-1068.

[11] Capio CM, Poolton JM, Sit CH, Holmstrom M, Masters RSW. Reducing errors benefits the fieldbased learning of a fundamental movement skill in children. Scandinavian Journal of Medicine \& Science in Sports 2013;23(2): 181-188.

[12] Capio CM, Poolton JM, Sit CH, Eguia KF, Masters RSW. Reduction of errors during practice facilitates fundamental movement skill learning in children with intellectual disabilities. Journal of Intellectual Disability Research 2013;57(4), 295-305.

[13] Ulrich D. Test of Gross Motor Development. Texas: Pro-Ed; 2000.

[14] Fleisig GS, Barrentine SW, Escamilla RF, Andrews JR. Biomechanics of overhand throwing with implications for injuries. Sports Medicine 1996;21(6):421-37. 
[15] Seroyer ST, Nho SJ, Bach BR, Bush-Joseph CA, Nicholson GP, Romeo AA. The kinetic chain in overhand pitching: its potential role for performance enhancement and injury prevention. Sports Health 2010;2(2):135-46.

[16] Roberton MA, Konczak J. Predicting children's overarm throw ball velocities from their developmental levels in throwing. Research Quarterly for Exercise and Sport 2001;72(2):91-103.

[17] Southard D. Changing throwing pattern: instruction and control parameter. Research Quarterly for Exercise and Sport 2006;77(3):316-25.

[18] Wulf G, McNevin N, Shea CH. The automaticity of complex motor skill learning as a function of attentional focus. Quarterly Journal of Experimental Psychology A 2001;54(4):1143-54.

[19] van Ginneken W, Capio CM, Poolton JM, Choi CSY, Masters RSW. The effect of errorless versus errorful learning on generalized motor program learning and parameterization learning. 19th Annual Congress of the European College of Sport Science. Amsterdam, The Netherlands 2014.

[20] Lorson KM, Stodden DF, Langendorfer SJ, Goodway JD. Age and gender differences in adolescent and adult overarm throwing. Research Quarterly for Exercise and Sport 2013;84(2):239-44. [21] Wells CL. Women, sport, and performance: A physiological perspective. Champaign, IL: Human Kinetics; 1991.

[22] Ohlsson S. Learning from performance errors. Psychological Review 1996;103(2):241-262.

[23] Thompson B. "Statistical," "practical," and "clinical": How many kinds of significance do counselors need to consider? Journal of Counseling and Development 2002;80(1):64-71.

[24] Cliff DP, Okely AD, Morgan PJ, Jones RA, Steele JR, Baur LA. Proficiency deficiency: mastery of fundamental movement skills and skill components in overweight and obese children. Obesity 2012;20(5):1024-33. 
Table 1. Descriptive data on participants' practice performance, movement pattern, and mastery scores.

\begin{tabular}{lcccc}
\hline & \multicolumn{1}{c}{ Typically developing (TD) sample } & Intellectual disability (ID) sample \\
& Error-reduced (ER) & Error-strewn (ES) & Error-reduced (ER) & Error-strewn (ES) \\
\hline $\begin{array}{l}\text { Practice } \\
\text { performance scores }\end{array}$ & $89.85 \pm 15.75$ & $82.41 \pm 13.69$ & $71.60 \pm 22.67$ & $51.23 \pm 25.19$ \\
$\begin{array}{l}\text { Pretest movement } \\
\text { pattern score }\end{array}$ & $6.72 \pm 1.57$ & $6.70 \pm 1.68$ & $2.73 \pm 0.80$ & $2.78 \pm 2.07$ \\
$\begin{array}{l}\text { Posttest movement } \\
\text { pattern score }\end{array}$ & $7.86 \pm 0.64$ & $7.43 \pm 1.29$ & $5.87 \pm 1.81$ & $4.44 \pm 1.88$ \\
$\begin{array}{l}\text { Pretest mastery } \\
\text { Posttest mastery }\end{array}$ & $47.8 \%$ & $46.8 \%$ & $0.0 \%$ & $4.8 \%$ \\
\hline
\end{tabular}

\section{Figure Legend}

Figure 1. Change in scores in overhand throwing movement pattern components in typically developing children (a) and children with intellectual disability (b). 
Figure 1

(a)
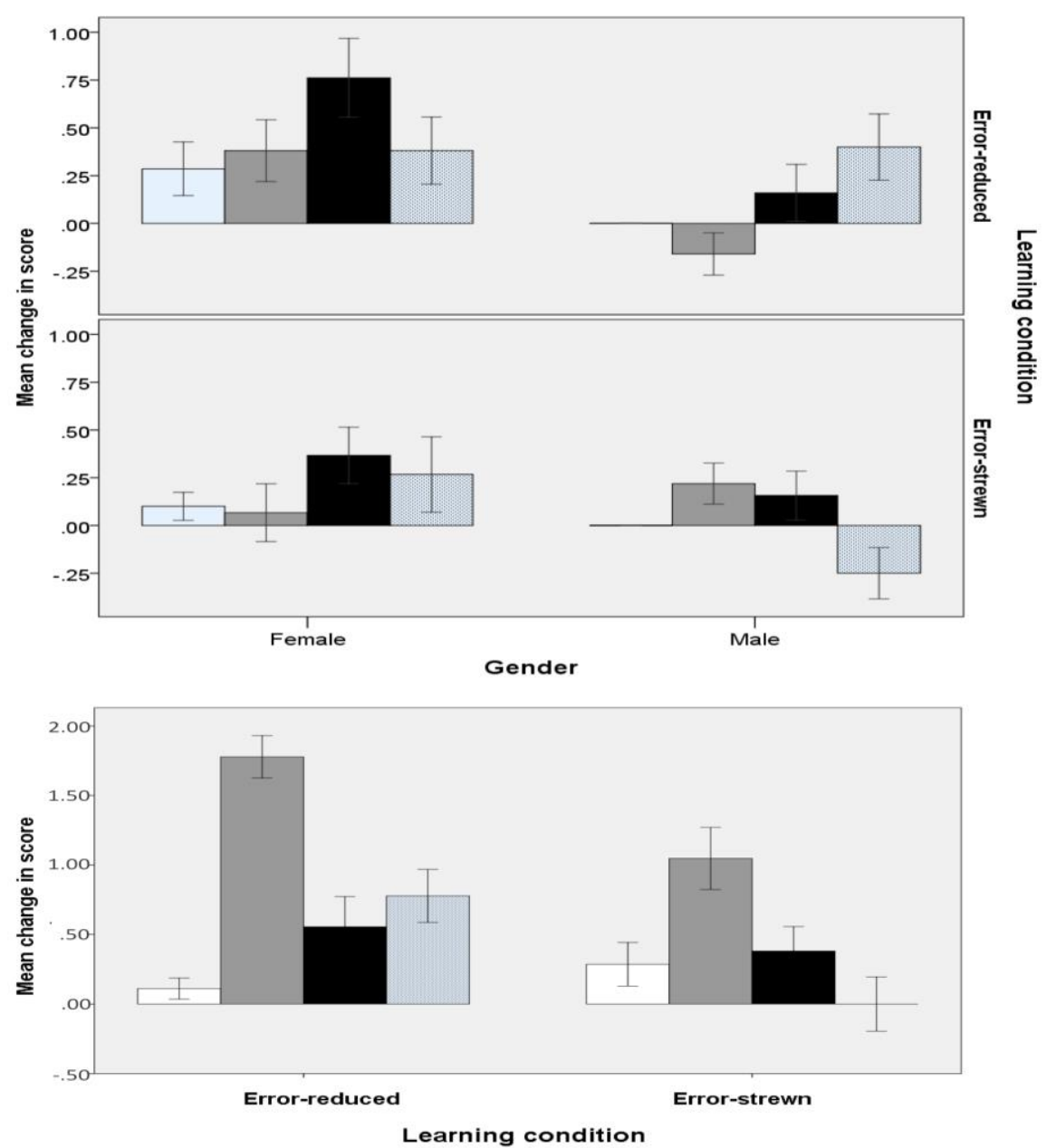